I shall be obliged if those who have opportunities of examining banks of dry and fine sand inclined at $3 \mathrm{I}^{\circ}$ will report through your columns whether they yield deep sounds when disturbed.

Cairo, April Io. H. CARRINGTON BOL.TON.

\section{AIR-TIGHT SUBDIVISIONS IN SHIPS.}

THE last two months have been unfortunate ones for shipping generally, and more particularly for the navies of at least four of the great powers. France has lost two torpedo boats under such circumstances as to involve the condemnation of a whole class of vessels. Germany and the United States of America have each lost a small fleet in a hurricane of unusual violence. Besides the material loss of ships these three nations have to bemoan the loss of a considerable number of men. Only little more than a month ago one of the largest ships of the British Navy stranded in waters rightly assumed to be perfectly safe, and has become a total wreck. Fortunately in this case there was no loss of life. Another of her H.M. ships only just escaped the disaster which overwhelmed the German and American fleets at Samoa, and the circumstances attending her escape are worthy of a moment's attention.

The storm approached not without warning, and it is evident that the captains of all the ships set about making preparations for meeting it as best they might. They appear all to have got up steam, so as to ease their cables by steaming to their anchors, in case it should be impossible to get out. The only ship that did get out was H.M.S. Calliope, and without in any way detracting from the merits of her captain and those under his order ; it is evident, from the brief accounts to hand, that all would probably have been unavailing had she not been provided with very powerful machinery. In the Navy List her tonnage is given as 2770 , and her horse power as 4020 , or one and a half indicated horse power per ton of displacement. The most powerful of the other ships was the German corvette Olga, which apparently had considerably less than one horse power per ton of displacement.

The other ships, especially the American ones, were so deficient in power that they were unable to make any front to the storm at all. Even with her great power the Calliope was only able to attain an effective speed of half a knot per hour in the teeth of the storm. All praise is due to the men who were able to make such good use of this very meagre margin as to have saved a costly ship and many valuable lives for the further service of their country.

The Samoan disaster has thus, in a dramatic and even tragic way, shown the uses of steam power in saving a vessel by propelling her against a storm. Reflections on the loss of the Sultan lead us to ask if steam power cannot be made more useful in succouring and saving a ship after sbe has struck a rock, or in any other way received such damage to her hull as to render her loss by foundering imminent.

According to convention an engine is working at the rate of one horse power when it is lifting a weight of one ton against gravity at a velocity of 14.74 feet per minute. If, then, a ship is fitted with engines indicating one horse power per ton of displacement, these engines would, if their whole power could be usefully applied and directed against gravity, be able to keep the ship afloat so long as she did not sink at a greater rate than $14^{\circ} 74$ feet per minute. The Vanguard took seventy-two minutes to sink. The practical question comes to be, How can the ship's power, of engines or men, be best applied so that the greatest proportion of it may be made available for keeping her from sinking?

Hitherto it has been usual to fit all ships with suction pumps, capable of being worked, some by steam and some by hand power. To use such pumps with effect it is necessary that they should be worked at such a rate as to throw overboard more water than can enter the ship in a given interval of time. The lower they bring the water in the hold of the damaged ship, the greater is the facility offered for the water to enter, and the harder becomes the work of lifting it. If the damage to the ship's hull is in any way serious, dealing in this way with its effect is almost always hopeless, unless it is possible to get at the leak and reduce its dimensions or close it altogether. The bottom of a ship at sea is very inaccessible. If she remains fast on the rock it is usually impossible to get at the leak either from the outside or from the inside. If she is afloat, and will keep afloat long enough, the leak can often be efficiently dealt with by passing a tarpaulin or sail under her bottom. But this is by no means a simple or easy operation, even when performed as a matter of drill with plenty of time, and in the absence of excitement or danger.

When a ship is sinking, she does so because water has got into her either from above or below, and has displaced the air with which she was charged. In order to stop her sinking and to raise her to her original level, it is necessary to reverse the operation and replace the water again by air. If the water has come in from above, by shipping seas, this can be effected by suction pumps, which throw it overboard again. If it has entered and is entering through a hole in the bottom of the vessel, it is necessary not only to remove the water which has entered, but to stop any further entry, and this is achieved by any means which enables us to thrust the water out again by the same way as that by which it entered.

If we consider a ship's hold, and assume that the deck covering it above, and the bulkheads shutting it off fore and aft, are all sufficiently strong and air-tight, then, if the whole bottom were allowed to drop out, her stability being otherwise assured, she would be very little the worse ; the water would rise in her hold only until it had so far compressed the air that its tension exactly balanced the pressure of the column of water outside, and matters might safely remain in this condition of equilibrium almost indefinitely. Thus, by making the main deck of a modern ship, to which the water-tight bulkheads are carried up, air-tight, she would be practically proof against all risk of sinking from damage to her bottom.

I do not think that there would be any difficulty in making the compartments of a ship perfectly air-tight, or more properly, in fitting them so that the rise of tension quickly produced by the entry of water through a serious leak, would at once close any joints or small openings, in the same way as the door of the air lock giving entrance to a submarine caisson is kept closed and airtight by the pressure of the air within. But inasmuch as the smallest leak of air, whether through the deck or through the bulkheads, would represent an equivalent of water entered and of buoyancy lost, it is necessary to be able to make good the loss by mechanical means. The more carefully the decks and bulkheads have been fitted in the first instance, the less will be the amount of air which will be required to be supplied by engine or man power in order to keep the water out in the event of serious damage to the ship's bottom.

Dealing with leaks in this way is equivalent to trans ferring the leak from the ship's bottom to her deck, and dealing with it there in the shape of an escape of air in place of an entrance of water.

In order to make successful use of this method it is necessary that the ship's deck and bulkheads should be not only air-tight, but also sufficiently strong to resist a pressure which, in the case of even the largest ships, would not exceed one atmosphere, or 15 pounds per square inch. Each compartment would have to be about as strong as an old low-pressure marine boiler.

Modern men-of-war are built in such a way that they require nothing but the air-tight hatches, and air-forcing 
pumps to make them quite secure against the most extensive damage to their bottoms. Indeed, as regards the stoke-holds, they are already fitted with the air-tight hatches in order to be able to used forced draught for the furnaces. Modern merchant ships are built with an iron deck, so that there is no difficulty about providing the strength. Their hatchways are, however, always very large; but, on the other hand, there is little traffic through them, so that they could be treated in a more substantial way than the smaller hatchways of a man-of-war with her large complement of men. The bulkheads which subdivide the hold into compartments always profess to be water-tight, and to be able to resist the pressure exercised by the water filling the compartment. There should therefore be no difficulty about them. Indeed, if ships were built to withstand air pressure, a very simple method would be provided for testing the efficiency of the bulkheads without the disagreeable process of filling the compartment with water. It would be only necessary to close the legitimate openings and get the air in it up to a pressure equal to that of the ship's draught of water, and the result would be unequivocal. It is proper to observe that the construction of an air-tight bulkhead would differ slightly from that of a water-tight bulkhead, inasmuch as it will be exposed to the maximum pressure over its whole surface, whereas the water-tight bulkhead is exposed to a graduated pressure, being greatest at the keelson, and least under the deck.

A further advantage of fitting a ship with air-tight subdivisions is, that it not only gives her greater security against foundering, but it affords a means of largely insuring her against risks of fire. This has more especial reference to merchant ships. If the contents of a ship's hold catch fire, the easiest way of putting it out is to stop the supply of air, and this can be done if the hold is air-tight.

So far the damage to the ship is supposed to be a rent in the bottom. If it is not in the bottom, but somewhere above it, then the air can only expel the water down to the level of the breach, when the air will begin to escape through its uppermost part. It will now depend on the supply of forced air available, how large a hole can be kept continuously filled by a stream of air rushing out. The area so occupied is necessarily closed to the entrance of water, and if the machinery can supply air at a sufficient rate, the whole rent can be filled by a current of air, which, so long as it is kept up, is as efficient a leak stopper as a plate of iron would be, and meantime the bottom of the hold can be cleared by the ordinary bilge pumps.

Rents in a ship's side, such as are produced when she is run down, or rammed by another, are usually so extensive and serious that, unless the ship is protected by an inner skin, immediate destruction ensues before there is time to take any measures for rescuing her. But with an inner skin the damage may be so far reduced as to make it possible to deal with it as above indicated. The higher up on the ship's side is the damage the less suitable is the pneumatic method for dealing with it, if it is of a really extensive character ; but, on the other hand, the more easy is it (given the time) to get at it, and deal with it from the outside. In all cases where the ship has been damaged by touching the ground, or by torpedo explosion under the bottom, and not involving the destruction of the ship, the pneumatic method affords the readiest means of combating the results.

It must be remembered that a ship's hold when filled with compressed air will be habitable; that is, if an air lock is provided, men can descend into it and repair the damage, just as they can descend into a caisson and dig out the foundations for the pier of a bridge.

The pneumatic method is however not only adapted for keeping damaged vessels afloat, it is also useful for raising sunken or stranded ships. For this purpose the salvage steamer must be provided with air-forcing pumps as well as the suction pumps which she usually carries. Having closed, and if necessary strengthened the deck, by means of divers if below water, she then pumps air into the holds of the ship, and at once restores a large proportion of her original buoyancy to her. If she does not rise, the other methods of salvage can be applied in addition, and with much increased chance of success.

The principle of this method is not new. A very old device in endeavouring to float, or to keep afloat, ships, is to fill as much of their damaged hold as possible with empty casks. A later modification of this method is to use inflatable india-rubber bags. It may be remembered that after the Vanguard sank Admiral Popoff of the Russian Navy sent a large apparatus of this kind in order to render assistance in trying to float her. Both these appliances are cumbersome: A ship's hold is seldom quite empty when she sinks, and even if it were, it is not easy to fill it under water with casks full of air, or even with inflatable air bags; and in any case it is difficult in this way to fill more than a fraction of the hold with air. The simple and efficient way of dealing with the matter is to treat the ship's hold itself as the vessel to be filled with air.

Compressed air is every day occupying a wider field as a means of transmitting power. It is already used as a substitute for gunpowder in the guns for firing shells with high explosives. It seems to me that if it can be used for largely increasing the safety of life and property at sea it is right that the fact should be brought as prominently forward as possible, in the hope that it may receive practical application in the hands of the shipbuilder and the engineer. J. Y. BUCHANAN.

\section{NOTES ON STANLEY'S JOURNEY.}

I HAVE watched every footstep of Stanley for the past twenty years, had constant intercourse with him during his short visits to this country, and have unbounded confidence in him as a pioneer, for I cannot but admire the noble efforts he has made to open up Africa to civilization. Wherever he has travelled he has left his mark behind him; others may follow his example without fear of being molested, and he has given us such vivid descriptions of the regions mapped by him that, for all practical purposes, no traveller need supervise his work. Some say he has been too high-handed with the natives, but I may be allowed to think that his power of influencing those over whom he holds command has proved him to be the most trusted and successful traveller of the age. If his explorations be quickly and judiciously followed up, the native inhabitants will feel security against all oppression, and the traders in slaves will be expelled from the country.

Brilliant is scarcely the name to give the exploit of Mr. Stanley, as given in his recently published letters. What instance in travel can excel such devotion? Is there a schoolboy who does not admire a man with his indomitable pluck and dogged perseverance? His latest journey to relieve Emin Pasha has outstripped, if possible, all his previous explorations in the "Dark Continent." Those I6o days of toil, from June 28 to December I2, I888, through starvation, desertion, mutiny, savage dwarfs and cannibals, thorny thickets, darkness, and swamps, were enough to try the patience of any human being; but, thank God, his British pluck never failed him; on and on he pressed, while his native followers were in utter despair, and broke out into mutiny. He used every persuasion with them : all failed. What was he to do? He felt that his duty was to relieve Emin Pasha-his countrymen expected this - and, with his accustomed sense of what was just and right, the two ringleaders of the mutinous band 